\title{
Kinetic modeling of gas phase sugar cracking to glycolaldehyde and other oxygenates
}

Schandel, Christian Bækhøj; Høj, Martin; Osmundsen, Christian Mårup; Beier, Matthias Josef; Taarning, Esben; Jensen, Anker Degn

\section{Published in:}

ACS Sustainable Chemistry and Engineering

Link to article, DOI:

10.1021/acssuschemeng.0c07232

Publication date:

2021

Document Version

Peer reviewed version

Link back to DTU Orbit

Citation (APA):

Schandel, C. B., Høj, M., Osmundsen, C. M., Beier, M. J., Taarning, E., \& Jensen, A. D. (2021). Kinetic modeling of gas phase sugar cracking to glycolaldehyde and other oxygenates. ACS Sustainable Chemistry and Engineering, 9(1), 305-311. https://doi.org/10.1021/acssuschemeng.0c07232

\section{General rights}

Copyright and moral rights for the publications made accessible in the public portal are retained by the authors and/or other copyright owners and it is a condition of accessing publications that users recognise and abide by the legal requirements associated with these rights.

- Users may download and print one copy of any publication from the public portal for the purpose of private study or research.

- You may not further distribute the material or use it for any profit-making activity or commercial gain

- You may freely distribute the URL identifying the publication in the public portal 


\section{Kinetic Modelling of Gas Phase Sugar Cracking to Glycolaldehyde and Other Oxygenates}

Christian Bækhøj Schandel[a], Martin Høj[a], Christian Mårup Osmundsen[b], Matthias Josef Beier[b], Esben Taarning[b], Anker Degn Jensen*[a]

[a] Department of Chemical and Biochemical Engineering, Technical University of Denmark, Søltofts plads, 2800 Kgs. Lyngby

[b] Haldor Topsøe A/S, Haldor Topsøes Allé 1, 2800 Kgs. Lyngby

aj@kt.dtu.dk

\section{Abstract}

Sugars can be cracked in a fluidized bed of glass beads to glycolaldehyde and various other oxygenate products that are valuable molecules on their own, or as platform molecules for conversion into other chemicals. In this work, cracking of sugars was investigated experimentally and a kinetic model was developed. The model is based on calculated reaction rate parameters for isomerization and retro-aldol reactions available in the literature. The set of parameters was expanded with empirical reaction rate parameters obtained from fitting the kinetic model to experiments feeding glycolaldehyde and 1,3-dihydroxyacetone. The kinetic model was validated against experiments of glucose, fructose and xylose cracking in the temperature range $440-600{ }^{\circ} \mathrm{C}$. The experimental total carbon balances varied with the type of sugar and operating temperatures in the range $77-97 \mathrm{wt} \% \mathrm{C}$. The temperature optimum for glycolaldehyde production was generally captured well by the kinetic model, however the yield was overpredicted by the model $(5-15 \mathrm{wt} \% \mathrm{C})$ for all sugars.

\section{Keywords: biomass $\bullet$ glycolaldehyde $\bullet$ pyrolysis $\bullet$ fluidized bed $\bullet$ retro-aldol $\bullet$ kinetic model}

\section{Introduction}

Significant attention is being directed towards the development of processes that utilize biomass to provide renewable solutions for chemical processes that may replace or supplement existing fossil-based solutions. ${ }^{1}$ For this, sugars are attractive candidates as feedstock for production of renewable chemicals, as they are a chemically well-defined form of biomass that are produced globally on a large scale in high purity and quantity.

It has been shown that glucose can be converted to glycolaldehyde (GA) by cracking (hydrous pyrolysis) at $500-600{ }^{\circ} \mathrm{C}$ in a fluidized bed reactor with yields up to $74 \% .^{2-4}$ Other oxygenate products are also produced from glucose cracking such as glyoxal, pyruvaldehyde, acetol, acetic acid and formaldehyde.

GA is a potential renewable platform chemical, that can be converted to other useful chemicals such as ethylene glycol by catalytic hydrogenation, ${ }^{5}$ glycolic acid by oxidation, ${ }^{6}$ methyl vinyl 
glycolate (MVG) $)^{7-9}$ and ethanol amines. ${ }^{10-12}$ Currently, work is ongoing to produce ethylene glycol from sugars through GA. ${ }^{13}$

Considerable experimental and theoretical work has been carried out in the field of glucose pyrolysis including work on isotopically labelled glucose to elucidate reaction pathways, ${ }^{14-18}$ influence of operating condition $\mathrm{s}^{19-22}$ and reaction modelling., ${ }^{4,23}$ The experiments have generally been carried out using micro pyrolyzer reactors, where the sugar is in solid form. When this method is used, the yields of glycolaldehyde are generally low (5-6\%) and anhydrosugars are formed (6-12\%). ${ }^{19-22}$ However, when a fluidized bed reactor is used and the sugars are fed as aqueous solutions using a spray atomization nozzle, the product distribution is vastly different from that observed from solid sugar pyrolysis in micro pyrolyzers. Most noticeably, only small amounts of anhydrosugars are formed $(<1 \%)$, and the yield of glycolaldehyde is much higher (up to $73-74 \%$ ). ${ }^{3,4}$

13 Seshadri \& Westmoreland ${ }^{24}$ calculated gas phase kinetic parameters for pyrolysis of sugars based on quantum-chemical and statistical mechanics calculations and discussed the implications for cellulose pyrolysis. They calculated kinetic parameters for a number of reactions relevant to sugar cracking, including isomerization with the effect of water partial pressure and decomposition reactions by retro-aldol reactions.

In this work, a kinetic model was developed for the sugar cracking process. The model is based on the kinetic parameters for reactions calculated by Seshadri \& Westmoreland ${ }^{24}$ along with additional kinetic parameters for reactions such as reverse isomerization reactions and further oxygenate decomposition to permanent gases and other observed products. These parameters were fitted to experimental data from this work obtained feeding glycolaldehyde and 1,3dihydroxyacetone, and validated against experiments feeding glucose, fructose and xylose.

\section{Experimental section}

The experiments were carried out at $340-600^{\circ} \mathrm{C}$ in a $41 \mathrm{~mm}$ ID stainless steel fluidized bed reactor (Figure 1) heated using an electrical oven and loaded with $100 \mathrm{~g}$ of $90-150 \mu \mathrm{m}$ soda lime glass beads (Silibeads SOLID Micro Glass Beads, Sigmund Lindner) fluidized by 10 $\mathrm{NL} / \min \mathrm{N}_{2}$ fed through a bottom sintered quartz distributor plate. $10-20 \mathrm{wt} \%$ aqueous solutions of glucose, fructose, xylose, 1,3-dihydroxyacetone (DHA) or GA were fed to the reactor at $2.15 \mathrm{~g} / \mathrm{min}$ using a two-phase spray nozzle with $4 \mathrm{NL} / \mathrm{min} \mathrm{N}_{2}$ for atomization. The droplets evaporated upon entering the reactor, and the vapor residence time in the reactor was approximately 1 second at $515^{\circ} \mathrm{C}$. The products were passed through a cyclone operated at $220^{\circ} \mathrm{C}$ and subsequently condensed in a surface condenser at $2-3^{\circ} \mathrm{C}$. The condensed aqueous products were analyzed and quantified using HPLC, and gases were analyzed and quantified with a GC-FID/TCD, see the Supplementary Information (SI). Experiments were operated until steady-state was reached (typically $4-6$ hours). The experimental uncertainty on the total carbon balance was reported in a previous work to be $<1 \%{ }^{3}$ 


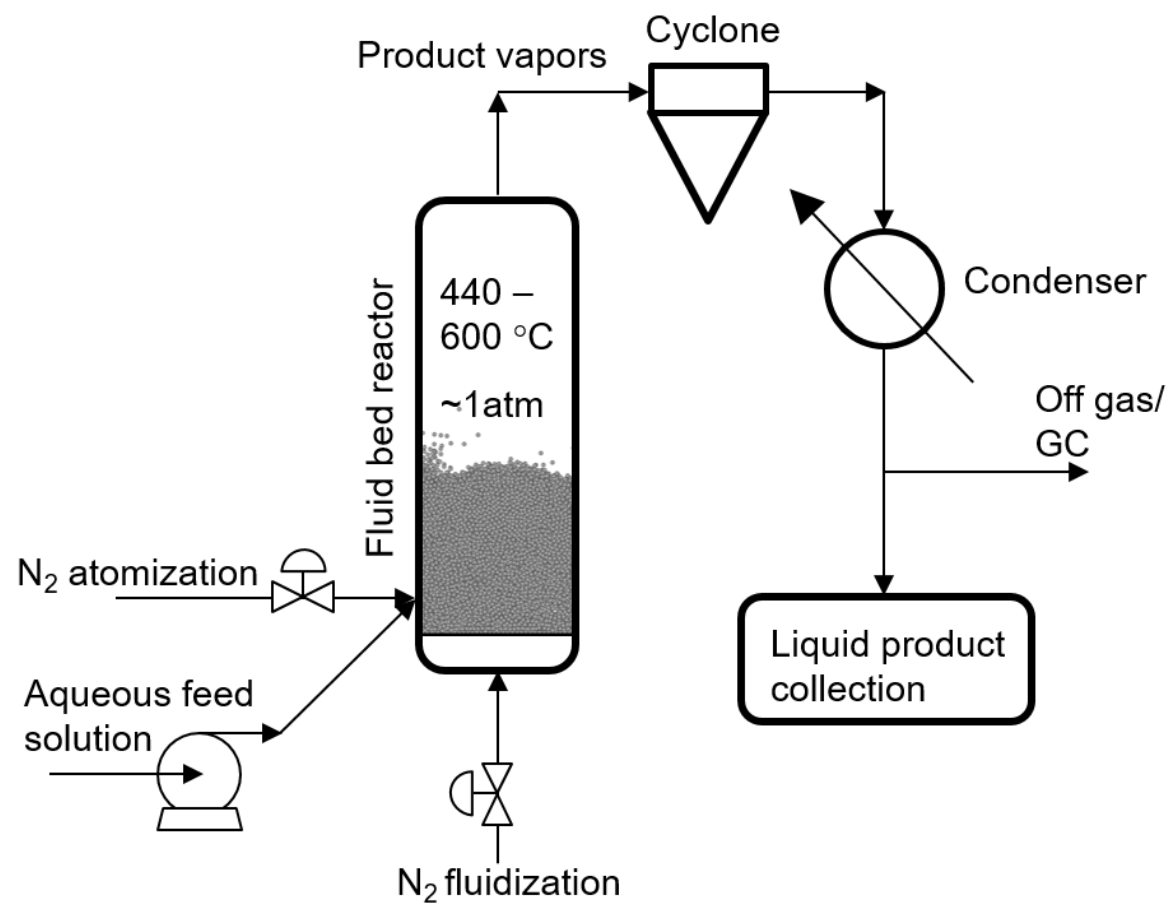

Figure 1: Experimental setup used for sugar cracking and kinetic studies.

\section{Model development}

4 The kinetic model developed in this work uses the kinetic parameters calculated by Seshadri \& Westmoreland, ${ }^{24}$ and while they calculated many of the reactions relevant for the sugar cracking process, there are limitations when comparing an initial kinetic model of sugar cracking, based solely on the reactions calculated by Seshadri \& Westmoreland, with experimental observations. Particularly, products not considered in their work are observed experimentally, such as pyruvaldehyde, acetol, glyoxal and permanent gases. ${ }^{3,4}$ Additional reactions were therefore proposed and modelled in this work in order to develop a kinetic model for the sugar cracking process. A simplified reaction network of the kinetic model developed in this work is shown in Figure 2, based on the work of Seshadri \& Westmoreland ${ }^{24}$ with the further reactions modelled in this work. In the sugar cracking process, the bed material is considered to be an inert heat carrier ensuring rapid heat transfer and is not further considered in the kinetic model. Any catalytic effect of the reactor wall is also neglected.

The most important reactions to add were related to further conversion of GA and DHA. GA is the main product, but it can thermally decompose to permanent gases (consisting experimentally primarily of $\mathrm{CO}$ and $\mathrm{CO}_{2}$, but also small amounts of methane, ethane and isobutane). DHA was not observed experimentally, while it is an end-product in the initial kinetic model. From experiments feeding GA and DHA, further empirical reactions were set up and their kinetic parameters fitted to the data assuming first-order reaction kinetics to describe formation of acetol and pyruvaldehyde, that were not considered in the work of Seshadri \& Westmoreland. ${ }^{24}$ 


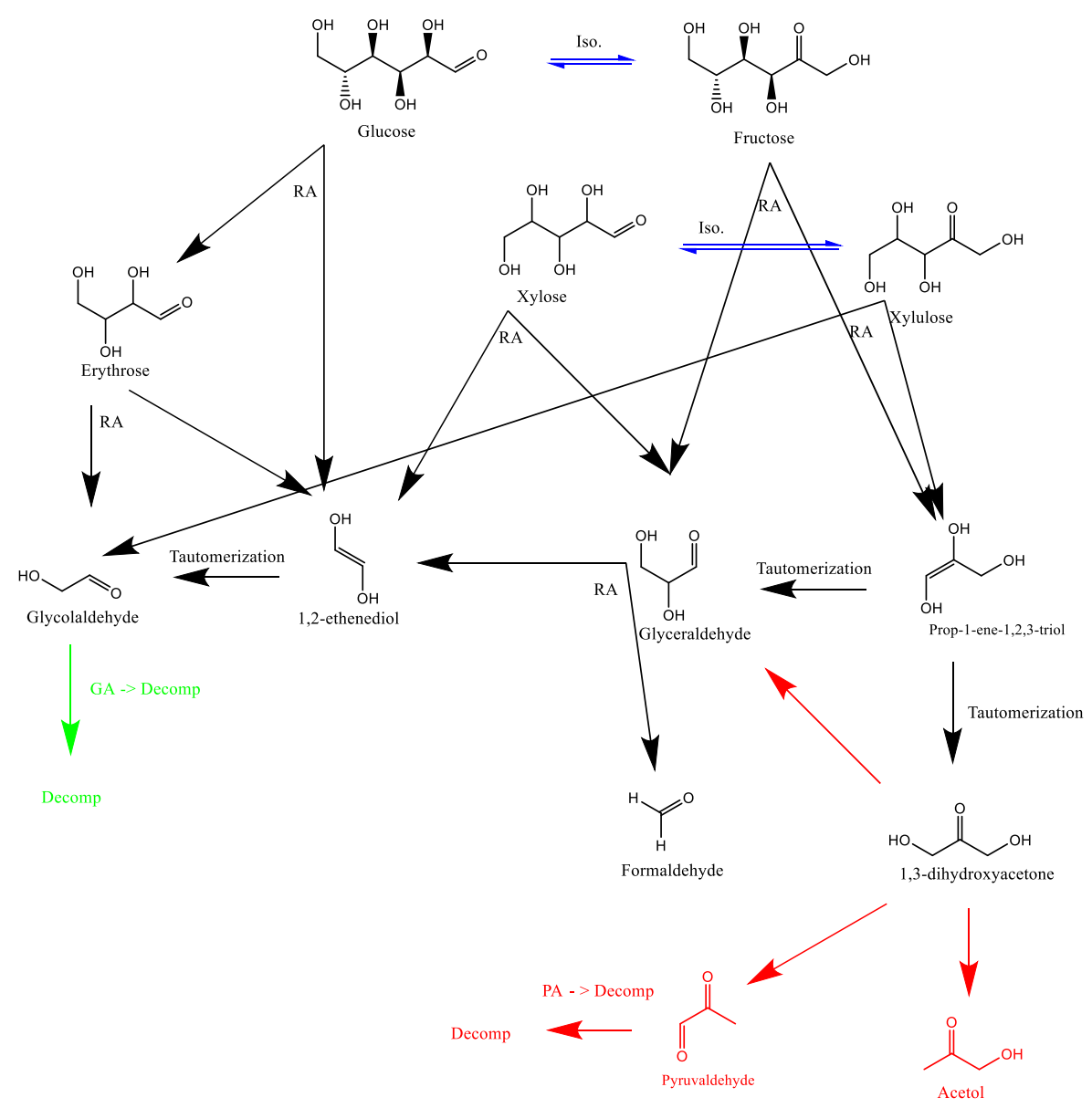

Figure 2: Simplified reaction network of the reactions in the present model. Black arrow reactions are from the work of Seshadri \& Westmoreland, ${ }^{24}$ green and red arrow reactions are obtained from fitting the kinetic model to experiments feeding GA and DHA, respectively. Blue arrows are reversible reactions determined by thermodynamic Gibbs free energy estimation (backward) and Seshadri \& Westmoreland (forward).

The sugar cracking process was modelled as an isothermal gas phase plug flow reactor, further assuming that the spray droplets instantaneously evaporated. A plug flow model was used as we assume intense mixing between the particles in the bed and feed from the nozzle creating a highly turbulent bed with no distinct bubbles. Reactions were either unimolecular $(\mathrm{u})$ or bimolecular (b, water-catalyzed) as shown below for reaction $i$ converting species $j$.

$$
\begin{gathered}
-r_{i, u, j}=k_{i, u} c_{j}=A_{i, u} \exp \left(\frac{-E_{i, u}}{R T}\right) c_{j} \\
-r_{i, b, j}=k_{i, b} c_{j} p_{H_{2} O}=A_{i, b} \exp \left(\frac{-E_{i, b}}{R T}\right) c_{j} p_{H_{2} O}
\end{gathered}
$$

The complete set of reactions is listed in the SI Table S1. Since the substrate and decomposition products are dilute in the gas phase under the operating conditions, as most of the gas phase consists of nitrogen and steam ( $>99 \mathrm{~mol} \%$ ), the total volumetric flowrate and water partial pressure were assumed constant throughout the reactor and the model was solved in terms of concentrations $c$ and residence-time $\tau$. 


$$
\frac{d c_{j}}{d \tau}=r_{j}
$$

1 The initial sugar concentration and the water partial pressure were calculated based on the feed conditions. The residence time was approximately $1 \mathrm{~s}$ at $515^{\circ} \mathrm{C}$ and was calculated based on flow conditions and the fluidized bed part of the reactor volume with a temperature correction:

$$
\tau_{\text {tot }}=\frac{515+273.15}{T} \cdot 1 s
$$

4 This part of the reactor was used, as the temperature rapidly drops in the freeboard (see SI

5 Figure S1)

6 The kinetic model was solved in MATLAB using the built-in solver ODE15s.

\section{Modelling empirical reactions}

9 Experiments feeding GA were used to quantify the formation of permanent gases at various 10 temperatures, and experiments feeding DHA were used to model formation of glyceraldehyde 11 (intermediate), acetol, pyruvaldehyde and its further conversion to permanent gases. The reactions were modelled as empirical reactions based on a carbon balance stoichiometry. The "Permanent gas" component is a pseudo component that is modelled as a $\mathrm{C}_{1}$ species with the concentration equal to the sum of permanent gas carbon $\left(\mathrm{CO}, \mathrm{CO}_{2}\right.$, methane, ethane and isobutane).

$$
\begin{gathered}
\text { Glycolaldehyde } \rightarrow 2 \text { Permanent gas } \\
D H A \rightarrow \text { Glyceraldehyde } \\
D H A \rightarrow \text { Pyruvaldehyde } \\
D H A \rightarrow \text { Acetol } \\
\text { Pyruvaldehyde } \rightarrow 3 \text { Permanent gas }
\end{gathered}
$$

First-order reaction kinetics was assumed and kinetic parameters were fitted to experimental data using minimization of residual squared sums with the built-in MATLAB function fmincon with equal weighting on each residual squared sum (glycolaldehyde, pyruvaldehyde, acetol, formaldehyde and permanent gases).

\section{Modelling reversible reactions}

22 Modelling of the reversible isomerization reactions of fructose to glucose and xylose to xylulose was carried out using the forward rate constants (assumed the same for xylose to xylulose as glucose to fructose) from Seshadri \& Westmoreland, ${ }^{24}$ and using the group additivity method of Han et al. ${ }^{26}$ to model the change in Gibbs free energy of the reactions to calculate the equilibrium constants and therefrom the rate of the reverse reactions:

$$
r_{i, j, u-}=k_{i, u-} c_{j}=\frac{k_{i, u}}{\exp \left(\frac{-\Delta_{r} G(T)}{R T}\right)} c_{j}
$$




$$
r_{i, j, b-}=k_{i, b-} c_{j}=\frac{k_{i, b}}{\exp \left(\frac{-\Delta_{r} G(T)}{R T}\right)} c_{j} p_{H_{2} O}
$$

1 Expressions for the relevant Gibbs free energies are given in the SI Table S2.

\section{Results and discussion}

\section{Results of fitting kinetic parameters}

5 The experimental data and the results of fitting the model for the decomposition of GA is shown in Figure 3. It can be seen that the yield of GA is captured well by the model. It was experimentally observed that some GA was converted to other oxygenates, resulting in an observed GA yield lower than $100 \%$ at all temperatures investigated. A correction was used to account for losses of GA: A constant loss of GA of about $10 \%$ was observed at lower temperatures in the range $340-420{ }^{\circ} \mathrm{C}$ and this fixed amount was used as a correction by adding it to GA data at all temperatures, corresponding to an assumption of no GA loss at low temperature. The complete experimental product distribution from the experiments can be seen in the SI Figure S2. The reaction was modelled by fitting to the GA yield (rather than permanent gases) as accurate modelling of the GA yield was prioritized. While the model shows a good fit to the observed GA yield, the corresponding formation of permanent gases does not fit the experimental data well at higher temperatures, as there is some temperature dependency on the formation of other oxygenates from GA. These byproducts include formaldehyde, glyoxal, acetic acid, pyruvaldehyde and acetol, and the nature of the formation of these products from GA is not included in the kinetic model. Some of these products have previously been observed in the literature. ${ }^{27,28}$ Furthermore, the total carbon balance for the experiments also decrease with temperature, which also contributes to the uncertainty at higher temperatures.

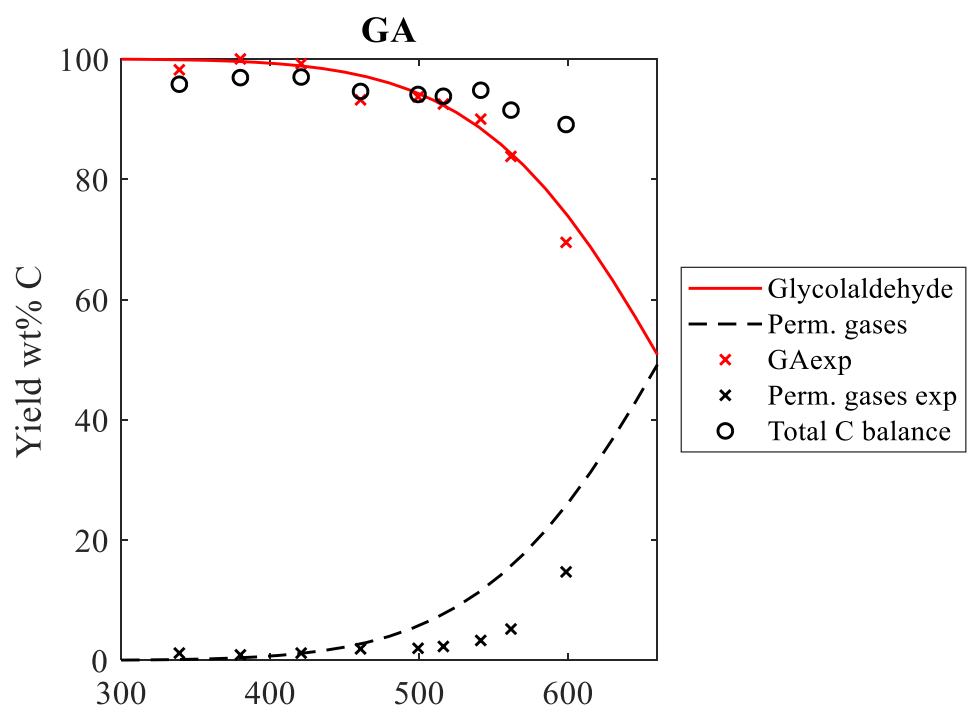

Figure 3: Experiments and kinetic model fit for GA decomposition. Reaction conditions: $2.15 \mathrm{~g} \mathrm{~min}^{-1} 10 \%$ aqueous GA solution, $14 \mathrm{NL} \min ^{-1} \mathrm{~N}_{2}, 100 \mathrm{~g}$ bed material. 
Experimental results and model fit for DHA decomposition are shown in Figure 4. Fitting of kinetic parameters to the empirical reactions of DHA (shown in Figure 2) showed reasonable agreement with the experimental data, capturing the optimum in the yield of GA, the decreasing yield of pyruvaldehyde at higher temperature, as well as the yields of acetol, formaldehyde and permanent gases. Kinetic parameters of the fitted reactions are shown in SI Table S1.

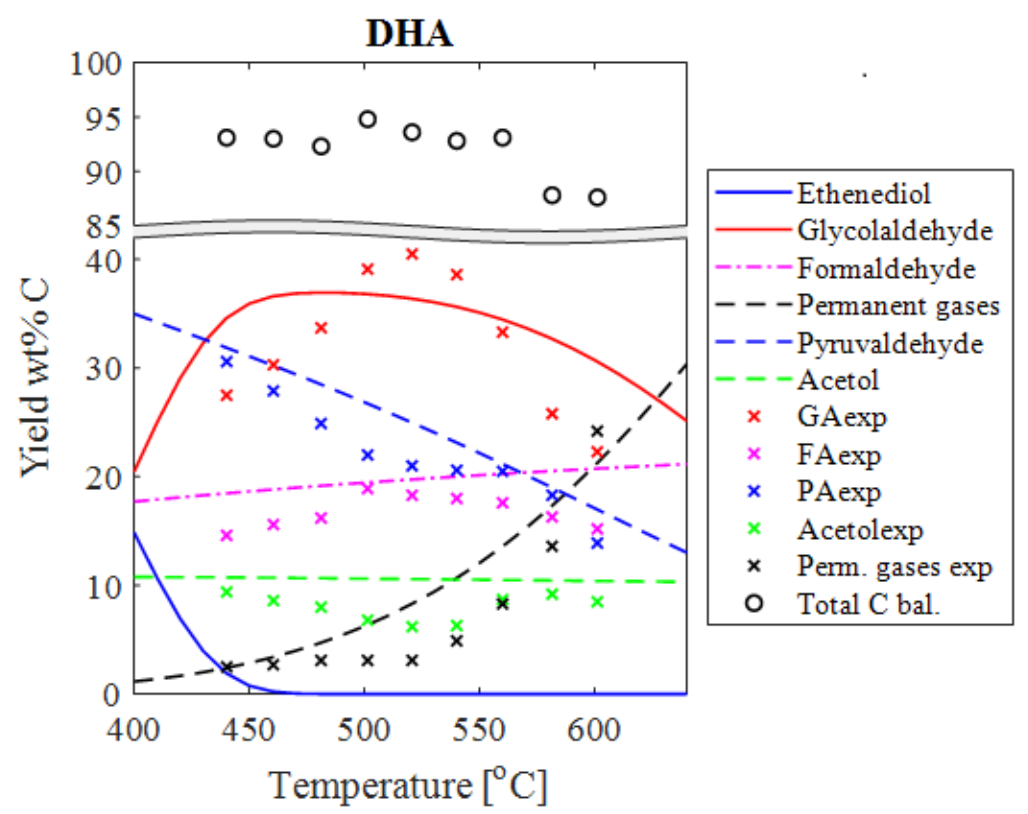

Figure 4: Experiments and kinetic model fit for DHA decomposition. Reaction conditions: $2.15 \mathrm{~g} \mathrm{~min}^{-1} 10 \%$ aqueous DHA solution, $14 \mathrm{NL} \min ^{-1} \mathrm{~N}_{2}, 100 \mathrm{~g}$ bed material.

\section{Experimental sugar cracking results and validation of the kinetic model}

The full kinetic model, including the empirical reaction kinetics obtained from fitting the GA and DHA decomposition experiments, was validated against cracking experiments of glucose, fructose, and xylose (Figure 5). Numerical values for experimental data points are shown in SI Table S3. Experimental data from these experiments were not used for parameter fitting. The model solution for the initial model is shown in SI Figure S2. In the initial model, the GA optimum yield is not captured as the secondary decomposition, which becomes important at high temperature, was not included. Furthermore, pyruvaldehyde and acetol were not included in the model, and 1,3-dihydroxyacetone, an end product in the initial model, was not observed experimentally.

The experimental yield of glycolaldehyde was generally higher at lower temperatures for glucose and fructose cracking. At temperatures lower than $500^{\circ} \mathrm{C}$, the fluidized bed reactor was increasingly difficult to operate for longer periods due to defluidization. It was possible to operate the xylose experiments at lower temperature (down to $440^{\circ} \mathrm{C}$ ) without defluidization, and a decrease in the yield of glycolaldehyde was observed below $480^{\circ} \mathrm{C}$. In general, the yield of glycolaldehyde increased in the order fructose $<$ xylose $<$ glucose, which is also expected from the reaction scheme in Figure 2, and shown previously in the literature. ${ }^{3}$ The yield of permanent gases (predominantly $\mathrm{CO}$ and $\mathrm{CO}_{2}$ ) from the various sugars was strongly influenced by the operating temperature. At $500{ }^{\circ} \mathrm{C}$, the yield was $2-3 \mathrm{wt} \% \mathrm{C}$ for all sugars, whereas it 
increased with temperature to 14,17 and $24 \%$ at $600{ }^{\circ} \mathrm{C}$ for glucose, xylose and fructose, respectively. The total carbon balance was also found to decrease at higher temperatures, especially for glucose and fructose, so the observed decrease in the condensed oxygenate yield was not fully accounted for by the increase in the quantified permanent gases. It may be that other compounds are formed at higher temperatures that are more difficult to condense, or increased formation of char, which is not quantified.

The yield of glycolaldehyde was overpredicted by the model for all sugars at all temperatures, however the temperature range with optimum GA yield at $500-520{ }^{\circ} \mathrm{C}$ is captured well for all sugars. The deviation may be due to formation of other products from reactions not included in the kinetic model such as reactions forming other oxygenates or char, which may be more important at higher temperatures where the carbon balances are lower. Furthermore, the yields predicted by the model strongly depend on the relative reaction rates of isomerization and retro-aldol reactions. Retro-aldol reaction of glucose without isomerization to fructose would produce only glycolaldehyde, while isomerization to fructose prior to retro-aldol reaction also produces $\mathrm{C}_{1}$ and $\mathrm{C}_{3}$, as discussed in relation to Figure 2 .

The formation of permanent gases was captured well for fructose decomposition, however the yield of permanent gases for xylose and glucose at higher temperatures was overpredicted by the model. It should be mentioned that these higher temperatures are outside the optimal temperature window for oxygenate production.

The results for the other condensed oxygenates, formaldehyde, pyruvaldehyde and acetol, are captured by the model to some extent. Acetol yields are generally captured well for all sugars at all temperatures. Pyruvaldehyde showed some deviation from the model, however the order of increasing yield was captured by the model: glucose $\approx$ xylose $<$ fructose. Formaldehyde was captured well by the model for glucose and xylose, but deviated more for fructose, especially at higher temperatures, where also the carbon mass balance was lower.

The deviation between experimental and predicted yields was likely due to experimental product losses in the system (as seen from low total $\mathrm{C}$ mass balances in some experiments) and limitations in the developed model. The model is an isothermal gas-phase reaction model, and droplet evaporation and interactions with the bed material or reactor wall is not considered. Furthermore, the kinetic reaction scheme is incomplete as it does not include all relevant reactions such as the formation of other byproduct oxygenates and char. Kostetskyy et al. ${ }^{4}$ found char yields below $0.025 \mathrm{wt}$. \% for cracking of glucose and fructose and thus seems unlikely to contribute significantly. It could be interesting to improve the model by performing additional experiments with other intermediate products e.g. glyceraldehyde and 1,2,3-prop-1ene-triol to better understand and model their decomposition pathways. However, these compounds were not available for experimentation. Furthermore, any secondary decomposition of formaldehyde or acetol, either thermally or surface-catalyzed, was not considered. They are however minor products and their yields are relatively stable with temperature for all the tested feedstock, so inclusion of their decomposition would not impact the modelling results significantly, however it could be a subject for further research. 
(a) Glucose

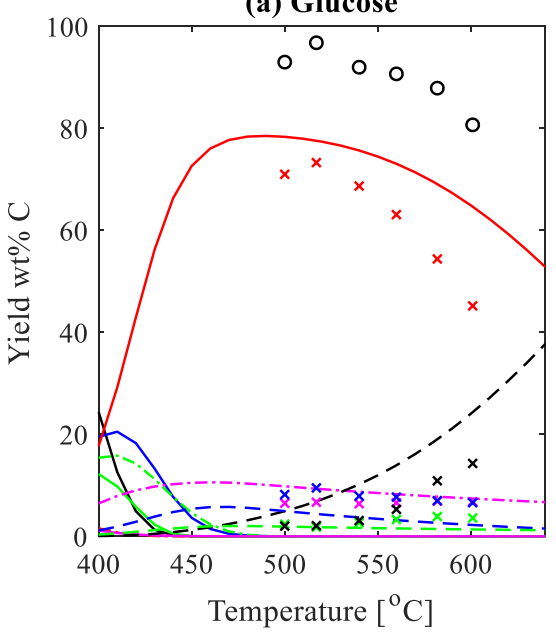

(c) Xylose

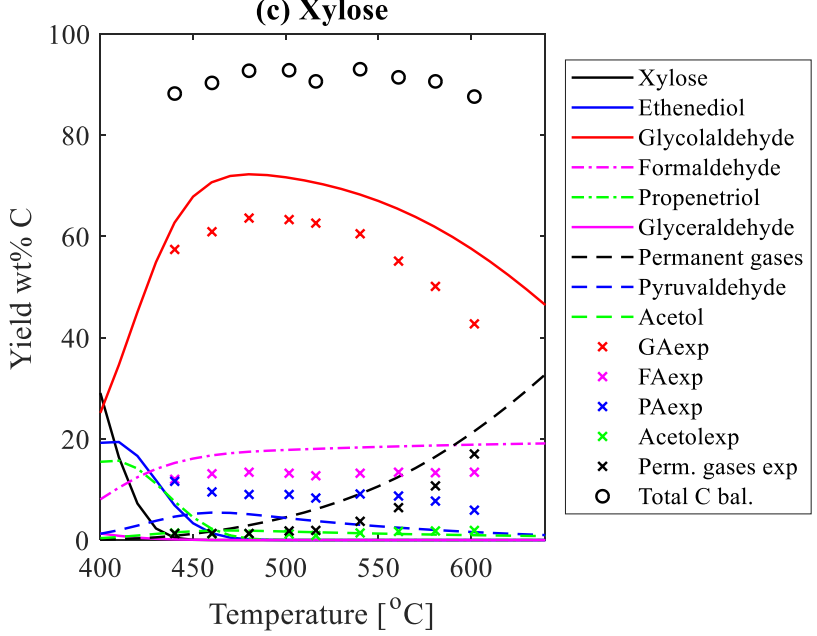

(b) Fructose

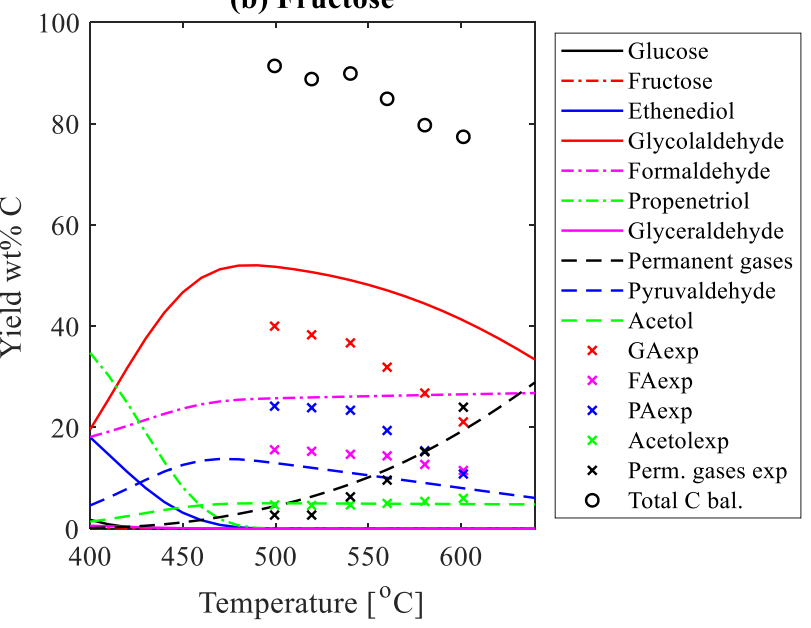

Figure 5: Sugar cracking experiments and model solution for glucose (a), fructose (b) and xylose (c). Reaction conditions: 2.15 $\mathrm{g} \mathrm{min}^{-1} 20 \%$ aqueous sugar solution, $14 \mathrm{NL} \min ^{-1} \mathrm{~N}_{2}, 100 \mathrm{~g}$ bed material.

The transient product distribution from the model at $515^{\circ} \mathrm{C}$ is shown in SI Figure S4 and show that the desired reactions take place on a timescale of $\sim 0.5 \mathrm{~s}$, after which only secondary decomposition to permanent gases take place. It would be interesting to further investigate the effect of residence time and to assess whether the kinetic model can be used to optimize the desired product yields in this regard.

\section{Conclusion}

12 Cracking of sugars by spraying an aqueous sugar solution into a hot fluidized bed is a promising method for production of renewable chemicals, such as glycolaldehyde, from renewable feedstocks. In this work, a kinetic model was presented for the sugar cracking process. The model was based on a set of reactions for glucose pyrolysis from the literature and was expanded with relevant isomerization reactions and empirically observed reactions related to glycolaldehyde and 1,3-dihydroxyacetone forming additional oxygenate products and permanent gases. The kinetic model was validated against experimental data for the cracking of glucose, fructose and xylose. The model was able to capture key observations from cracking of the various sugars at different temperatures including the optimum temperature range for 
the yield of glycolaldehyde and the relative product distribution between different sugars. The model may be further improved by investigating the cracking of intermediate species such as glyceraldehyde and 1,2,3-prop-1-ene-triol.

Gammel konklusion:

Cracking of sugars by spraying an aqueous sugar solution into a hot fluidized bed is a promising method for production of chemicals, such as glycolaldehyde, from renewable feedstocks. However, a better understanding of the chemistry is required to optimize the yields of the desired products, such as glycolaldehyde - a potential platform molecule in a renewables based chemical industry. A set of reactions for glucose pyrolysis from the literature was used as starting point to build a kinetic model for the sugar cracking process. The model was expanded with relevant isomerization reactions and empirically observed secondary reactions related to glycolaldehyde and 1,3-dihydroxyacetone forming additional oxygenate products and permanent gases. The kinetics of the empirical reactions were determined by assuming instantaneous vaporization of the feed and plug flow of gas, and fitting first-order reactions kinetics to data from separate experiments with these species. The final kinetic model for sugar cracking was validated against experimental data for the cracking of glucose, fructose and xylose in a fluidized bed reactor when spraying an aqueous feed. The model was able to capture key observations from cracking of the various sugars at different temperatures. Although the yield of the desired product GA was overpredicted by the kinetic model by $5-15$ $\mathrm{wt} \% \mathrm{C}$, the temperature range for optimum glycolaldehyde yield was well captured. At higher temperatures, the experimental total carbon mass balance decreased, and the model fit was generally found to be poorer for all sugars.

\section{References}

(1) Bomgardner, M. M. A New Dawn for Biobased Chemicals? Chem. Eng. News 2020, 98 (26), 28-33.

(2) Majerski, P. A.; Piskorz, J. K.; Radlein, D. S. A. G. Production of Glycolaldehyde by Hydrous Thermolysis of Sugars. US 7094932B2, 2002.

(3) Schandel, C. B.; Høj, M.; Osmundsen, C. M.; Jensen, A. D.; Taarning, E. Thermal Cracking of Sugars for the Production of Glycolaldehyde and Other Small Oxygenates. ChemSusChem 2020, 13 (4), 688-692.

(4) Kostetskyy, P.; Coile, M. W.; Terrian, J. M.; Collins, J. W.; Martin, K. J.; Bradzil, J. F.; Broadbelt, L. J. Selective Production of Glycolaldehyde via Hydrothermal Pyrolysis of Glucose: Experiments and Microkinetic Modeling. J. Anal. Appled Pyrolysis 2020, 149, 104846.

(5) Osmundsen, C. M.; Taarning, E.; Larsen, M. B. Process for the Preparation of Ethylene Glycol from Sugars. US 20170197893A1, 2017.

(6) Osmundsen, C. M.; Taarning, E. A Method and a System for Producing Glycolic Acid 
and/or Glycolate. WO 2018/095973 A1, 2018.

(7) Dusselier, M.; Van Wouwe, P.; De Smet, S.; De Clercq, R.; Verbelen, L.; Van Puyvelde, P.; Du Prez, F. E.; Sels, B. F. Toward Functional Polyester Building Blocks from Renewable Glycolaldehyde with Sn Cascade Catalysis. ACS Catal. 2013, 3 (8), 1786-1800.

(8) De Clercq, R.; Dusselier, M.; Dijkmans, J.; Iacobescu, R. I.; Pontikes, Y.; Sels, B. F. Confinement Effects in Lewis Acid-Catalyzed Sugar Conversion: Steering Toward Functional Polyester Building Blocks. ACS Catal. 2015, 5 (10), 5803-5811.

(9) Tolborg, S.; Meier, S.; Saravanamurugan, S.; Fristrup, P.; Taarning, E.; Sádaba, I. Shape-Selective Valorization of Biomass-Derived Glycolaldehyde Using Tin-Containing Zeolites. ChemSusChem 2016, 9 (21), 3054-3061.

(10) Faveere, W.; Mihaylov, T. T.; Pelckmans, M.; Moonen, K.; Hamers, F. G.; Bosschaerts, R.; Pierloot, K.; Sels, B. F. Glycolaldehyde as Bio-Based C2 Platform Chemical : Catalytic Reductive Amination of Vicinal Hydroxyl Aldehydes. ACS Catal. 2019.

(11) Mägerlein, W.; Melder, J.-P.; Jörg, P.; Eberhardt, J.; Krug, T.; Kreitschmann, M. Reactions of Glycolaldehyde with an Aminating Agent. US20120271068A1, 2012.

(12) Liang, G.; Wang, A.; Li, L.; Xu, G.; Yan, N.; Zhang, T. Production of Primary Amines by Reductive Amination of Biomass- Derived Aldehydes / Ketones. Angew. Chemie - Int. Ed. 2017, 56 (11), 3050-3054.

(13) Haldor Topsøe A/S. Braskem and Haldor Topsoe start up demo unit for developing renewable MEG https://blog.topsoe.com/braskem-and-haldor-topsoe-start-up-demounit-for-developing-renewable-meg.

(14) Paine, J. B.; Pithawalla, Y. B.; Naworal, J. D.; Thomas, C. E. Carbohydrate Pyrolysis Mechanisms from Isotopic Labeling. Part 1: The Pyrolysis of Glycerin: Discovery of Competing Fragmentation Mechanisms Affording Acetaldehyde and Formaldehyde and the Implications for Carbohydrate Pyrolysis. J. Anal. Appl. Pyrolysis 2007, 80 (2), 297311.

(15) Paine, J. B.; Pithawalla, Y. B.; Naworal, J. D. Carbohydrate Pyrolysis Mechanisms from Isotopic Labeling. Part 2. The Pyrolysis of d-Glucose: General Disconnective Analysis and the Formation of $\mathrm{C} 1$ and $\mathrm{C} 2$ Carbonyl Compounds by Electrocyclic Fragmentation Mechanisms. J. Anal. Appl. Pyrolysis 2008, 82 (1), 10-41.

(16) Paine, J. B.; Pithawalla, Y. B.; Naworal, J. D. Carbohydrate Pyrolysis Mechanisms from Isotopic Labeling. Part 3. The Pyrolysis of d-Glucose: Formation of C3and C4carbonyl Compounds and a Cyclopentenedione Isomer by Electrocyclic Fragmentation Mechanisms. J. Anal. Appl. Pyrolysis 2008, 82 (1), 42-69.

(17) Paine, J. B.; Pithawalla, Y. B.; Naworal, J. D. Carbohydrate Pyrolysis Mechanisms from Isotopic Labeling. Part 4. The Pyrolysis of d-Glucose: The Formation of Furans. $J$. Anal. Appl. Pyrolysis 2008, 83 (1), 37-63.

(18) Paine, J. B.; Pithawalla, Y. B.; Naworal, J. D. Carbohydrate Pyrolysis Mechanisms from Isotopic Labeling. Part 5. The Pyrolysis of D-Glucose: The Origin of the Light Gases from the D-Glucose Molecule. J. Anal. Appl. Pyrolysis 2019, 138 (September 2018), 
70-93.

(19) Zhou, X.; Nolte, M. W.; Mayes, H. B.; Shanks, B. H.; Broadbelt, L. J. Experimental and Mechanistic Modeling of Fast Pyrolysis of Neat Glucose-Based Carbohydrates. 1. Experiments and Development of a Detailed Mechanistic Model. Ind. Eng. Chem. Res. 2014, 53 (34), 13274-13289.

(20) Patwardhan, P. R.; Satrio, J. A.; Brown, R. C.; Shanks, B. H. Product Distribution from Fast Pyrolysis of Glucose-Based Carbohydrates. J. Anal. Appl. Pyrolysis 2009, 86 (2), 323330.

(21) Patwardhan, P. R. Understanding the Product Distribution from Biomass Fast Pyrolysis, Iowa State University, 2010.

(22) Mettler, M. S.; Paulsen, A. D.; Vlachos, D. G.; Dauenhauer, P. J. The Chain Length Effect in Pyrolysis: Bridging the Gap between Glucose and Cellulose. Green Chem. 2012, $14(5), 1284$.

(23) Zhou, X.; Nolte, M. W.; Shanks, B. H.; Broadbelt, L. J. Experimental and Mechanistic Modeling of Fast Pyrolysis of Neat Glucose-Based Carbohydrates. 2. Validation and Evaluation of the Mechanistic Model. Ind. Eng. Chem. Res. 2014, 53 (34), 13290-13301.

(24) Seshadri, V.; Westmoreland, P. R. Concerted Reactions and Mechanism of Glucose Pyrolysis and Implications for Cellulose Kinetics. J. Phys. Chem. A 2012, 116 (49), 11997-12013.

(25) Vinu, R.; Broadbelt, L. J. A Mechanistic Model of Fast Pyrolysis of Glucose-Based Carbohydrates to Predict Bio-Oil Composition. Energy Environ. Sci. 2012, 5 (12), 98089826.

(26) Han, K.; Jamal, A.; Grambow, C. A.; Buras, Z. J.; Green, W. H. An Extended Group Additivity Method for Polycyclic Thermochemistry Estimation. Int. J. Chem. Kinet. 2018, 50 (4), 294-303.

(27) Wang, D. Catalytic Steam Reforming of Biomass-Derived Oxygenates: Acetic Acid and Hydroxyacetaldehyde. Appl. Catal. A Gen. 1996, 143 (2), 245-270.

(28) Porterfield, J. P.; Baraban, J. H.; Troy, T. P.; Ahmed, M.; McCarthy, M. C.; Morgan, K. M.; Daily, J. W.; Nguyen, T. L.; Stanton, J. F.; Ellison, G. B. Pyrolysis of the Simplest Carbohydrate, Glycolaldehyde (CHO-CH2OH), and Glyoxal in a Heated Microreactor. J. Phys. Chem. A 2016, 120 (14), 2161-2172. 